\title{
Second order motion compensated spin-echo diffusion tensor imaging of the human heart
}

\author{
Christian T Stoeck ${ }^{1,2^{*}}$, Constantin von Deuster ${ }^{1,2}$, Martin Genet ${ }^{1}$, David Atkinson ${ }^{3}$, Sebastian Kozerke ${ }^{1,2}$ \\ From 18th Annual SCMR Scientific Sessions \\ Nice, France. 4-7 February 2015
}

\section{Background}

Stimulated echo acquisition mode (STEAM) [1] imaging has been used to probe myocardial microstructure invivo. However STEAM imaging requires $2 \mathrm{R}-\mathrm{R}$ intervals, sophisticated respiratory navigator gating [2] and is subject to myocardial strain $[3,4]$. Spin-echo (SE) based single-shot diffusion weighted sequences present an appealing alternative $[5,6]$. In this work the sensitivity to bulk motion of cardiac SE diffusion tensor imaging is addressed by using second order motion compensated (MC) diffusion encoding.

\section{Methods}

First and second order MC diffusion encoding gradients were incorporated into a cardiac triggered single-shot $\mathrm{SE}$ sequence (Figure 1). Imaging was performed on a $1.5 \mathrm{~T}$ Philips Achieva system (Philips Healthcare, Best, The Netherlands) equipped with gradients delivering $80 \mathrm{mT} /$ $\mathrm{m} @ 100 \mathrm{mT} / \mathrm{m} / \mathrm{ms}$. Five healthy volunteers were imaged with navigator-gating during free-breathing with the following parameters: resolution: $2.2 \times 2.2 \mathrm{~mm}^{2}$, slice thickness: $6 \mathrm{~mm}$, local-look FOV: $230 \times 98 \mathrm{~mm}^{2}$, TR/TE: $1 \mathrm{R}-\mathrm{R} /$ $83 \mathrm{~ms}$, two slices (apex/base). Fat suppression was incorporated by spectral-spatial excitation. Three orthogonal diffusion encoding directions $\left(b=450 \mathrm{~s} / \mathrm{mm}^{2}, 8\right.$ averages) were applied at trigger delays ranging from $45 \mathrm{~ms}$ to peak systole (steps of 10ms). Ten diffusion directions (10 averages, TR: $2 \mathrm{R}-\mathrm{R}$ ) were acquired in an additional session at 38\%/47\%/ $56 \% / 66 \% / 75 \%$ peak systole. The mean diffusivity (MD) was calculated as function of trigger delay and used as measure for the sensitivity to bulk motion. Helix angles were calculated upon tensor reconstruction.

'Institute for Biomedical Engineering, University and ETH Zurich, Zurich, Switzerland

Full list of author information is available at the end of the article

\section{Results}

$\mathrm{MD}$ as function of trigger delay is shown in Figure 2a). Second order MC diffusion encoding yielded an applicable trigger delay range of $15-81 \%$ (apical) and $15-77 \%$ (basal) of peak systole. For first order MC, the corresponding trigger delay windows were only $30-57 \%$ (apical) and $27-56 \%$ (basal). Figure $2 b$ ) shows a time series of helix angle maps (basal) and the transmural angle histograms (apical/basal) c).

\section{Conclusions}

Second order motion compensated cardiac SE diffusion encoding significantly decreases the sensitivity to bulk motion compared to first order motion compensated diffusion gradients across the heart.

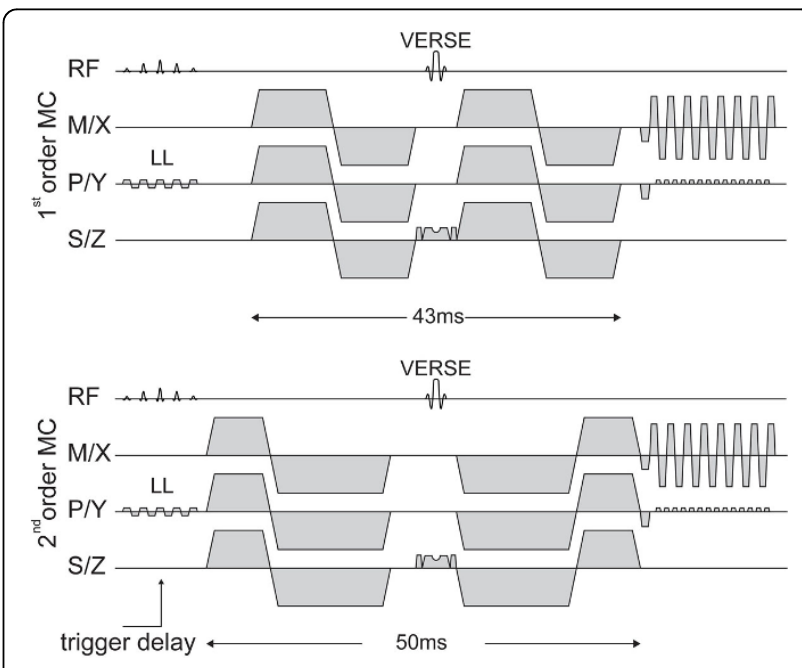

Figure 1 Sequence diagram of first and second order motion compensated (MC) diffusion imaging. A spatial spectral reduced field of view (LL) excitation is used for fat suppression. A variable rate selective excitation (VERSE) echo pulse is used for refocussing. 


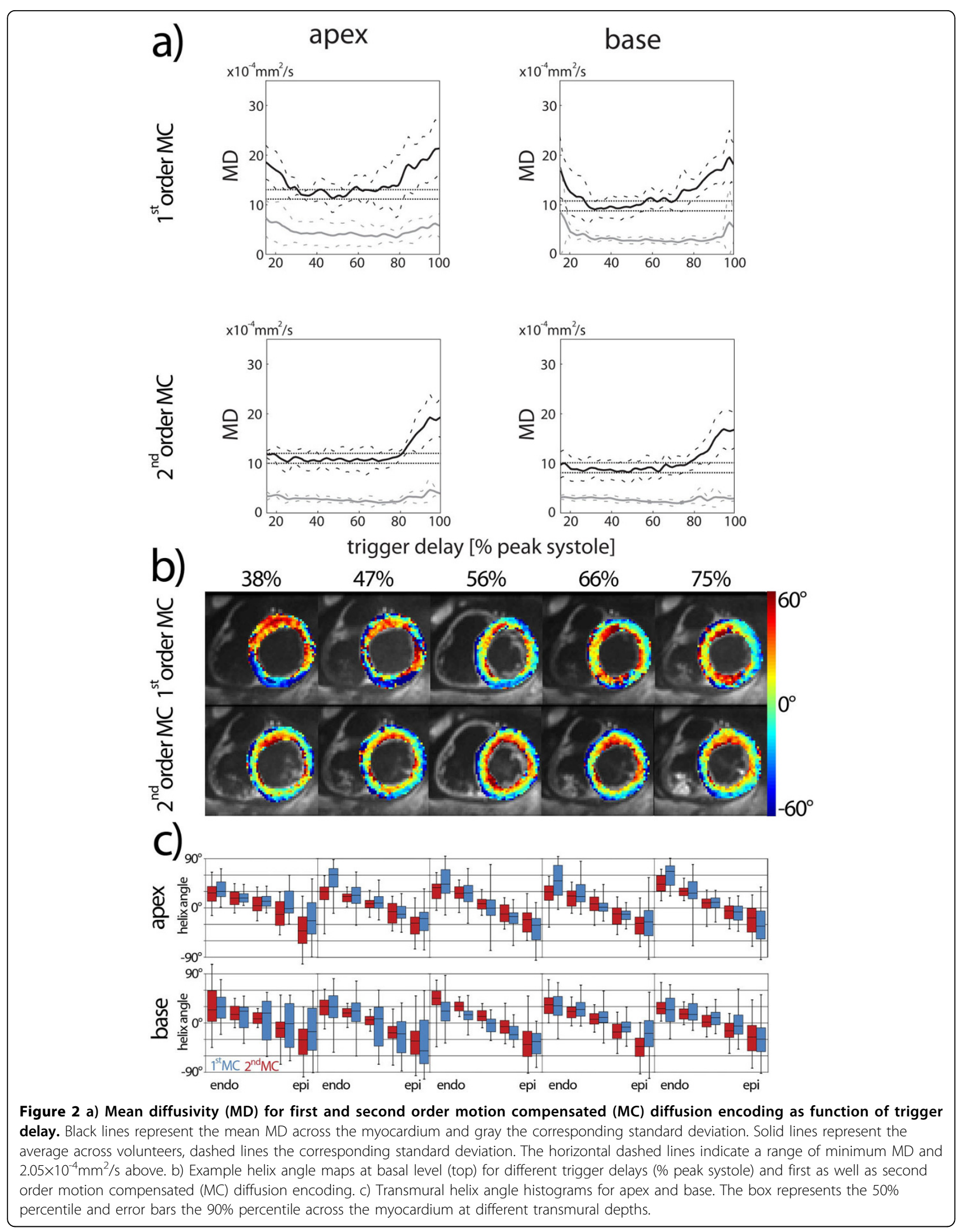




\section{Funding}

Swiss National Science Foundation, grant \#CR3213_132671/1, EU FP7 Marie-Curie fellowship to MG, UK EPSRC, grant EP/I018700/1.

\section{Authors' details}

${ }^{1}$ Institute for Biomedical Engineering, University and ETH Zurich, Zurich, Switzerland. ${ }^{2}$ Imaging Sciences and Biomedical Engineering, King's College London, London, UK. ${ }^{3}$ Centre for Medical Imaging, University College London, London, UK.

Published: 3 February 2015

\section{References}

1. Edelman, et al: MRM 1994

2. Nielles-Vallespin, et al: MRM 2013.

3. Reese, et al: MRM 1995.

4. Stoeck, et al: PLOS ONE 2014

5. Gamper, et al: MRM 2007.

6. Nguyen, et al: MRM 2013.

doi:10.1186/1532-429X-17-S1-P81

Cite this article as: Stoeck et al: Second order motion compensated spin-echo diffusion tensor imaging of the human heart. Journal of Cardiovascular Magnetic Resonance 2015 17(Suppl 1):P81.

Submit your next manuscript to BioMed Central and take full advantage of:

- Convenient online submission

- Thorough peer review

- No space constraints or color figure charges

- Immediate publication on acceptance

- Inclusion in PubMed, CAS, Scopus and Google Scholar

- Research which is freely available for redistribution

Submit your manuscript at www.biomedcentral.com/submit 